Bramham, J., MacCarthy, B., \& Guinery, J. (2005). Managing product variety in quotation processes. Journal of Manufacturing Technology Management, 16(4), 411-431.

\title{
Managing product variety in quotation processes
}

\author{
Jo Bramham, Bart MacCarthy and Jane Guinery \\ Mass Customization Research Centre, Operations Management Division, \\ Nottingham University Business School, Nottingham, UK
}

\begin{abstract}
Purpose - Manufacturers across many sectors increasingly operate in high variety environments.

Research evidence suggests that variety has a negative impact on performance. However, the research literature is limited on the enablers that allow variety to be managed effectively and efficiently at the "front-end" of an organisation and in quotation processes in particular.
\end{abstract}

Design/methodology/approach - This paper presents case analysis of the quotation processes from manufacturers operating in high-variety environments. Qualitative process modelling tools have been developed to allow representation of process complexities and informal process elements.

Findings - Findings are presented on generic mechanisms for absorbing and mitigating the impact of variety on quotation processes. A generic quotation process model is presented comprising four key decisions centres: customization request initiation and information gathering on customer needs, classification of requests, resource control, and identification of information for reuse.

Practical implications - The implications of the study for the automation of quotation processes in high variety and mass customization environments are discussed and it is speculated that different decision centres will dominate in different environments.

Originality/value - The generic model developed by this research offers insight into the functioning of the core process elements of the quotation system. Reviewing an organisation's structure and the information systems infrastructure supporting these decision centres should lead to the identification of potential system or reorganisation improvements.

Keywords Mass customization, Product adaptation, Order systems.

Paper type Research paper. 


\section{Introduction}

Recent trends show that variety is increasing across most sectors (Funke and Ruhwedel, 2000; Holweg and Greenwood, 2000). Indeed most manufacturing enterprises face mounting pressure to offer more variety. The core reasons for this are rooted in societal and economic changes, growth in consumer affluence and aspirations (Toffler, 1970). In business-to-business (B2B) environments, increases in variety may result from:

- the need to respond to customer requests by continually developing and expanding the product envelope; and

- the need to provide complete "solutions" to customers.

Such pressures may be due to the power of some customers in industrial markets to negotiate product specifications that are tailored to meet their requirements. The need to provide solutions is often driven by the level of competition in the market; intense competition means that innovative solutions are required beyond the scope of the current core product or product range, e.g. offering an additional service or integrating the product into a system.

The impact of variety has been studied in a number of sectors but has mostly concentrated on the management and control of manufacturing operations, particularly with respect to order fulfilment and quality (Stalk, 1988; Hayes and Wheelwright, 1984; Yeh and Chu, 1991; Anderson, 1995). Less research has been performed into the handling of variety at the front-end of the business particularly where the level of customer interaction may be significant with regard to product specification and quotation. The customer interface is critical to business success (Moos and Milling, 2002). This paper investigates the role of the customer interface in facilitating the quotation process. It focuses on the characteristics and management of quotation processes in high-variety environments.

Many businesses operating in industrial markets are adopting product configurator technologies to process customer requests for a broad range of product variants (Forza and Salvador, 2002). Such configurators typically supplement the functionality of ERP and production planning systems by providing an interface for customer choices - a customer variant bill of materials. ERP systems may constrain customer choice because they are based on the production structure required for variants (Kruse and Bramham, 2003).

Product configurators are typically set-up with the product options from which the customer can choose (often with sales assistance from sales and/or technical staff) and associated costs and lead times can be generated according to the customer specification. However, fully engineering a product before a customer enquiry is received is not the only way to present variant capability to customers and indeed may not be sufficient to provide variety that is focused on customer needs in particular environments. Spring and Darymple (2000) present evidence of manufacturers in business markets that need to provide continuously evolving product ranges driven by customer demand. Requests may be received from business customers that are outside the product range described by the product configurator. These may be "non-standard" products that warrant a cooperative response. The business must therefore provide some reactive decision making to consider the implications of modifications to existing product variants. This paper investigates how businesses can combine the "configure-to-order" approach with reactive decision making, specification and engineering, triggered by a non-standard request. 
The research investigates the characteristics exhibited by manufacturers who provide products to business markets. The aim is to identify mechanisms for providing rapid effective quotations and the constraints that may obstruct this. Being able to handle high levels of product variety in a responsive manner, both in terms of the customer interface and in order fulfilment, is a key enabler of mass customisation (MacCarthy et al., 2003). The study reported in the paper is based on an in-depth analysis of case studies undertaken by the authors. The analysis provides insights into the nature of the challenges faced, specifically in customer interaction processes, in two manufacturing enterprises operating in high-variety B2B environments. The paper analyses the organisational, informational and decision-making elements that support their quotation processes.

\section{Managing product variety}

Demands are being placed on existing operations to adapt to and ideally, to absorb increased levels of variety with minimal negative impact on performance or profit margins. There is some documented evidence to suggest that this is being achieved by a number of companies in some sectors (McDermott et al., 1997; MacDuffie et al., 1996). However, other studies show that businesses are incurring significant overhead costs with respect to management and control, particularly for customer-driven variety (Sievanen et al., 2000). Evidence suggests that a major part of the burden lies in customer interaction processes and in activities such as product specification for manufacture (Erens and Hegge, 1994). The research of Miller and Vollman (1985) quantifies this burden - they estimate that quality related transactions, which include product specification, constitute $25-40$ per cent of costs.

Some research has highlighted the challenge of managing the additional activities that are required to respond to "new" customer requests (Amaro et al., 1999) and the conflict of managing these whilst avoiding deterioration in responsiveness (McCutcheon et al., 1994). This would indicate that managing high levels of product variety is a key challenge requiring important trade-offs between customer needs and the mitigation of negative impacts.

Much of the literature on managing product variety centres on the re-design of product architecture as the lever to manage costs whilst maintaining product choice - modularity has long been argued to be the solution to product complexity problems (Starr, 1965; Pine, 1993). However, Child et al. (1991) in their guidance on managing complexity suggest the deployment of a wide range of measures; including those not confined exclusively to the product development department. Their perspective is focussed on the avoidance of unnecessary variety and does not embrace the need for high levels of customer-driven variety. Miller and Vollman (1985) recommend the integration of information systems and the removal of manual handling of ordering to reduce costs. In the same vein, Swaminathan (2001) recommends standardization of processes. Another approach to managing variety is to separate it into different types and provide processes dedicated to each type (Skinner, 1974).

The findings of previous studies prompt many questions about the most effective approaches for the management of product variety in the front-end of the organisation and their relevance to quotation processes. Which management activities are effective in controlling the impact of variety? Can evidence of mechanisms that enable the management of high product variety be found? This research investigates two manufacturers with high product variety to explore these questions. 


\section{Conceptual framework}

A "quote" is a document that describes the commitment by a business to the customer in terms of product specification, price and delivery. A quote results from a quotation process that must convert a description of customer needs into organisational capabilities. Resources need to be provided within the front-end of the business to facilitate the quotation process. Resources will typically include information technology, stores of drawings of previous customer orders, product and process knowledge and individual expertise. The documented sections of the quotation process are the visible part of processing customer needs. However, verbal communications (particularly customer communications) may not be fully documented but may be an important element of the process. This means that the front-end resources consumed may not all be conspicuous from tracing the quotation paper trail. Process mapping tools are required to capture all decisions made and resources used including knowledge and expertise.

Figure 1 shows the conceptual framework adopted in the research. It shows the physical aspects of a quotation process that uses a product configurator. The figure highlights the people involved in supporting the quotation process. At the centre of the diagram is the quotation process. The next level comprises the front-end business system which operates within the business organisation characteristics and which is subject to environmental influences. The elements of the systems identified are typical but may not be explicit in all cases. By considering the system in terms of a number of hierarchical levels the influences on the design of the quotation process may be decomposed. This approach is recommended by Pettigrew (1992) for empirical studies in search of "holistic rather than linear explanations of processes". This holistic approach is important for analysis of the quotation process because the process is strongly interconnected with other systems such as the market and manufacturing systems and may in some cases hold significant stores of tacit organisational knowledge. This paper will conduct a first level of analysis by investigating the quotation process in detail.

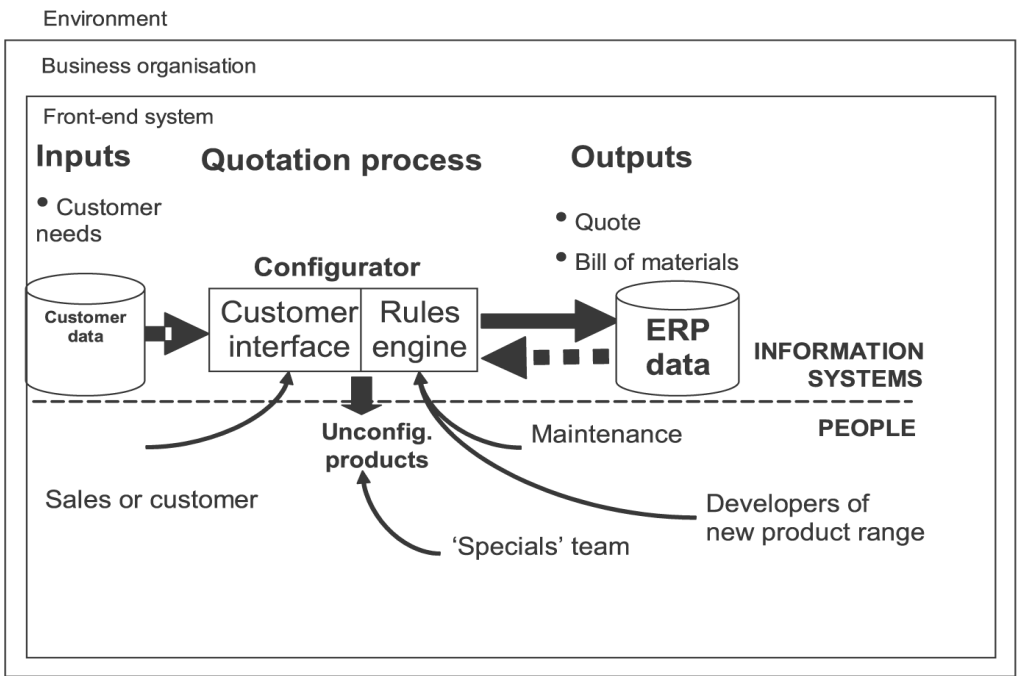

Figure 1. Conceptual framework of the quotation process 


\section{Methodology}

\section{Research approach}

The research approach adopted in this study is to explore

(1) the characteristics exhibited by two businesses;

(2) the processes used by these businesses to provide quotations to customers for configured and non-standard products; and

(3) the mechanisms and decision making that underpin these processes.

A case study approach is a proven method for collecting rich empirical evidence (Voss et al., 2002). It was for this reason that the case study approach to data collection and analysis was used. The case study unit of analysis used in the research was defined as the interface between customers and the company. Interviews were conducted to give the qualitative evidence on the characteristics of quotation processes. Data were recorded using participant summary sheets and "memos" of emergent themes to inform the development of theory (Miles and Huberman, 1994).

\section{Company profiles}

The two businesses selected for the study were chosen because they represented two different approaches to managing product variety. The companies' identities have been protected to respect confidentiality but other than this, all of their characteristics and processes are presented unaltered.

The first business examined in this study, Seat Selector, manufactures office furniture in the UK to the individual specifications of business customers from around the world. The second business, Custom Instrument, provides customized instrumentation to aerospace, automotive and equipment manufacturers from a UK and US manufacturing base. This business has more complex quotation processes than Seat Selector and provides three case studies as the parent company and two of its international subsidiaries have been studied. Each has its own specific customer interface and markets. Both businesses provide "call-off customization" (MacCarthy et al., 2003) where a non-standard product is requested on the basis that it is likely to be reordered. The implication of producing an "inaccurate" quotation is significant as the customer is likely to reorder that product and inaccuracies in lead time estimation or costs may also have long-term effects. The key characteristics of the two businesses are summarised in Table 1.

The first business, Seat Selector, utilises a high level of information technology to automate customer interface processes and related activities. In contrast, custom instrument's processes require a significant effort in manual processing and human decision making. Both companies offer a high level of variety across their product ranges but regularly, expand their product envelope due to requests from customers. Their product ranges also expand because of new product offerings involving new technologies, new designs, or solutions for niche markets. Both companies employ product configurators to piece together the customer's requirements from existing product elements but use them in different ways. The configurator also checks the feasibility of the product specification based on rules that have been embedded in the software. Once new products are established, these are often incorporated in the configurator or catalogue for the customer to reorder. 
Table 1. Profile of Seat Selector and Custom Instrument front-end characteristics

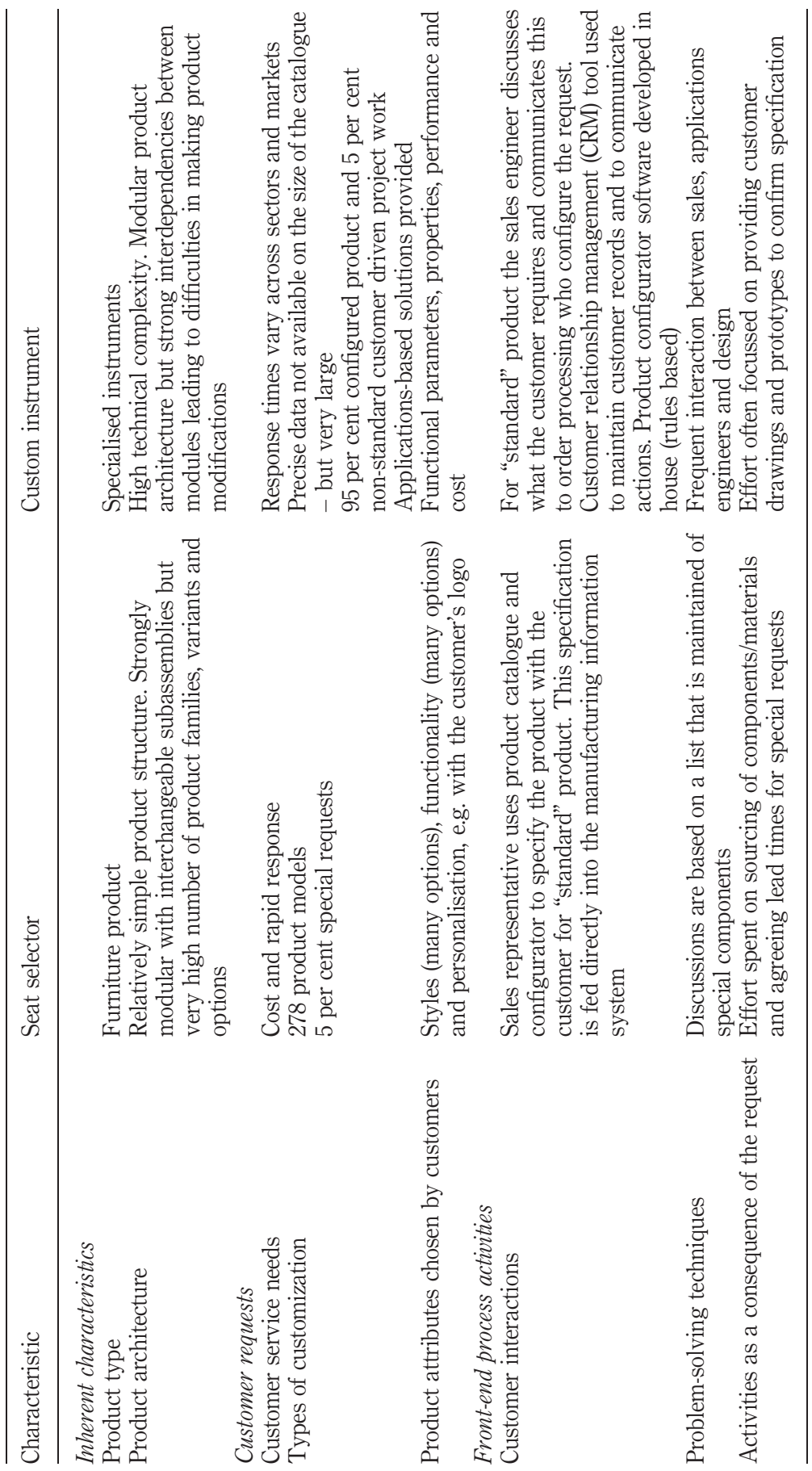


The study and analysis of the quotation processes informed the development of a conceptual model of generic quotation processes. De Bono (1998) recommends comparing a complex system against a simple model for decomposing complexity. The quotation process used by Seat Selector was well formalised with distinct process stages so it gave a valuable start point for a simple model that could be developed into a generic model.

\section{Data collection}

The participants in the study from Seat Selector were some of the important stakeholders' in the quotation process - the information systems manager and the operations director. They were interviewed on the nature of systems and processes. The second study at Custom Instrument necessitated the collection of more detailed information in order to understand the complexities of its quotation processes. Over 30 participants were interviewed in total. Their roles spanned all front-end functions - sales, engineering and product management. Meetings between these personnel and the production department for non-standard products were also recorded and analysed. Case studies were conducted for three of the customer interfaces of Custom Instrument, as follows:

(1) the head office sales team, which were co-located with the central design facility based in UK;

(2) a small subsidiary providing the customer interface for the French market, which relies on the central design facility because their local technical expertise is limited due to size of the organisation; and

(3) a large subsidiary providing the customer interface for the USA market, which not only has a local (decentralised) design facility but also uses the central design facility in the UK.

These three customer interfaces were examined and compared to understand the factors influencing the operation of the customer interface in providing a quote. This provided evidence on the impact of organisational structure on quotation decision making and how different communication mechanisms are used for conveying customer needs to the technical decision makers in different units.

\section{Development of methods for capturing and analysing quotation process}

Variety generates complexity (Child et al., 1991) and since the customer interface is exposed to the true variety of the market this is an area of the business that is likely to manifest process complexity. This agrees with the findings of Kingsman and de Souza (1997) who uncovered evidence of practices using over 200 rules to generate the cost information for quotations.

A tool kit of modelling techniques was assembled for the investigation including interview tools for process knowledge elicitation. Role activity diagramming was used to represent process stages and the division of activities across functions. Other process modelling tools needed to be developed including methods for describing information systems applications for each organisational function and interaction diagramming to represent different types of communication. 


\section{Aim of the analysis}

The analysis aimed to provide detailed sources of evidence for quotation processes and how they operate in order to support the development of a generic quotation process model. The analysis also sought evidence of "good practices" for managing variety in the front-end system. The evidence forms a basis to provide insights into process improvement opportunities in quotation processes for managers of front-end systems. The identification of process improvements is the guiding aim for this research.

\section{Findings}

\section{Conceptual model of process flow for quotation activities}

The research has developed a process model from Seat Selector showing key activities and communications. This "process flow of quotation activities" represents an important framework for the research study. It provides an initial model of a business offering twin modes of configure-to-order and custom engineering and offers a useful initial model of the quotation process against which other quotation process flows may be compared.

Key process stages have been identified from the evidence collected. These form the basis of the conceptual model of the quotation process:

(1) discussion of customer needs;

(2) consideration and development of quotation:

- assess feasibility of configuration to the customer's specification;

- refer to list of available options outside standard configuration;

. discuss modifications with interna| experts; and

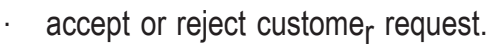

(3) presentation of quotation to the customer:

- present quotation;

- present quotation with sample/prototype; and

- present alternative product specification in a quotation.

(4) update of information systems including the product configurator.

Figure 2 shows a conceptual model that has been developed based on these key stages to represent generic process steps.

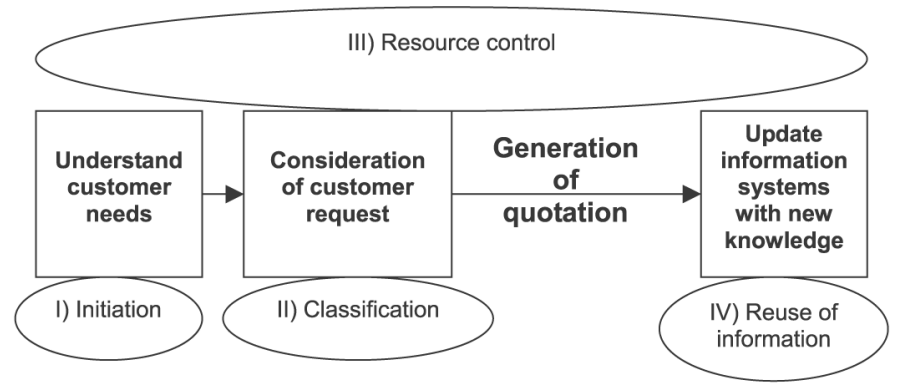

Figure 2. Quotation process stages and decision centres 


\section{Analysis of decision processes}

Capture of the quotation processes of Custom Instrument was more demanding because the key activities were more complex and less formalised than Seat Selector. Many of the process activities that varied from customer request to customer request were embedded in the process knowledge of key individuals. The investigation of the processes used by Custom Instrument provided the opportunity to extend the toolkit of process representation tools. Analysis of these informal processes allowed a model of key quotation decision centres to be developed where decision centres represent core elements of the front-end system. The conceptual model was developed based on the identification of key stages of the process.

Figure 3 shows how these decision centres are related to the key process stages in the conceptual model of the quotation process. This represents the quotation process as a cyclical process with information deemed to be valuable for reuse. The conceptual model represents the quotation process as a cycle. This begins with initiation of a customization request, followed by classification of the customization request. The final stage in the loop is the identification of information for reuse in further enquiries. Each stage has a decision centre in which people, with the support of information systems, make decisions on the information received and act to progress the customization request by generating and exchanging information. The first stage of the loop, decision centre (I) refers to diagnosis of customer needs. The second stage decision centre (II) represents diagnosis of customer needs within the organisation; internal constraints and requirements are assessed by the relevant experts. The final stage in the loop is decision centre (IV) that identifies information for reuse. At the centre is the sub-system relating to resource management. This is decision centre (III) and it is this decision centre that is central to all quotation stages. The decision centres are described in more detail in Table 2 using examples of the activities relating to the aims of each decision centre. Each decision centre is reviewed in turn against the evidence from Custom Instrument.

Decision centre (I) - customization request initiation and information gathering on customer needs: The customer interaction process model shown in Figure 4 illustrates the complexity of one of the customer interfaces at Custom Instrument using an example taken from the UK head-quarter sales staff responding to a UK customer request. The diagram is divided into communications relating to the initial enquiry and then revisions to the customer request when the order is placed. Many different organisational functions are involved in dialogue with the customer in some informal or formal way. Information gathering at Custom Instrument requires many different organisational functions to interact with the customer.

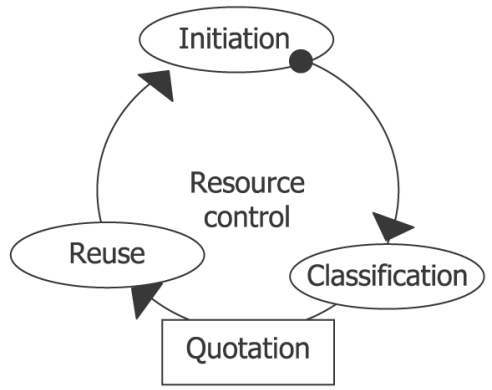

Figure 3.Quotation learning process and decision centres 
Table 2. Decision centres of the quotation process

\begin{tabular}{ll}
\hline Decision centre & Aims of the decision centres \\
\hline (I) Customization request initiation and & Collect information in dialogue with the \\
information gathering on customer needs & customer on their requirements \\
(II) Classification of requests & Route customer enquiries to the relevant \\
experts in the company & Understand the scale of the modifications \\
& to meet customer requirements \\
& Recognise the closest match product that \\
might be "cannibalised" to meet customer & needs or initiate new product development \\
& to meet customer needs \\
& Assign resources to the consideration of \\
& customer requests \\
& Assess what information is likely to be \\
useful in the future for further customer & orders or quotations \\
(III) Resource control & Analyse the feedback on the success of \\
(IV) Identification of information for reuse & quotions and accuracy of estimates \\
& associated with customization requests
\end{tabular}

Decision centre (II) - classification: At custom nstrument the classification of a request is agreed collaboratively by a group of people from different functions, e.g. product managers and engineers. The process flow for processing a customer enquiry through the US customer interface team is shown in Figure 5. This diagram was constructed using role activity diagramming techniques (Ould, 1995). The roles involved in each process step are diagrammed. This illustrates the complex nature of cross-functional collaboration.

Both the product range and the application domains for products at -ustom nstrument are very broad. Therefore, the knowledge is segmented into different expert roles associated with product types and applications, e.g. specific kinds of applications or specific sectors such as aerospace. A matrix organisation has evolved where technical expertise is divided across product managers and engineers. A problem for the organisation is that process and organisational knowledge is required to know which expert to access in the network and how to access them.

The model of decision centres (Figure 3) allows analysis of the three different organisational structures of the Custom Instrument case studies. Different challenges occur when there are local decentralised design facilities (such as in the US) or where these must be referred to UK headquarters. There are duplicate classification decision centres in the customer interface local to the US market and in the centralised decision facilities in the UK. This duplication can lead to reversal of decisions, e.g. a rejected enquiry becoming a live request.

Decision centre (III) - resource control: Organisational complexity is highlighted when decision centres are overlaid on an organisation chart. Key experts within a decision centre are often scattered across a number of functions. This means that management of human resources and expertise is difficult. No overarching manager was found who had visibility across the breadth of the quotation process. The holistic control of the process in these circumstances is difficult due to the fragmentation of managers' scope of responsibility. 


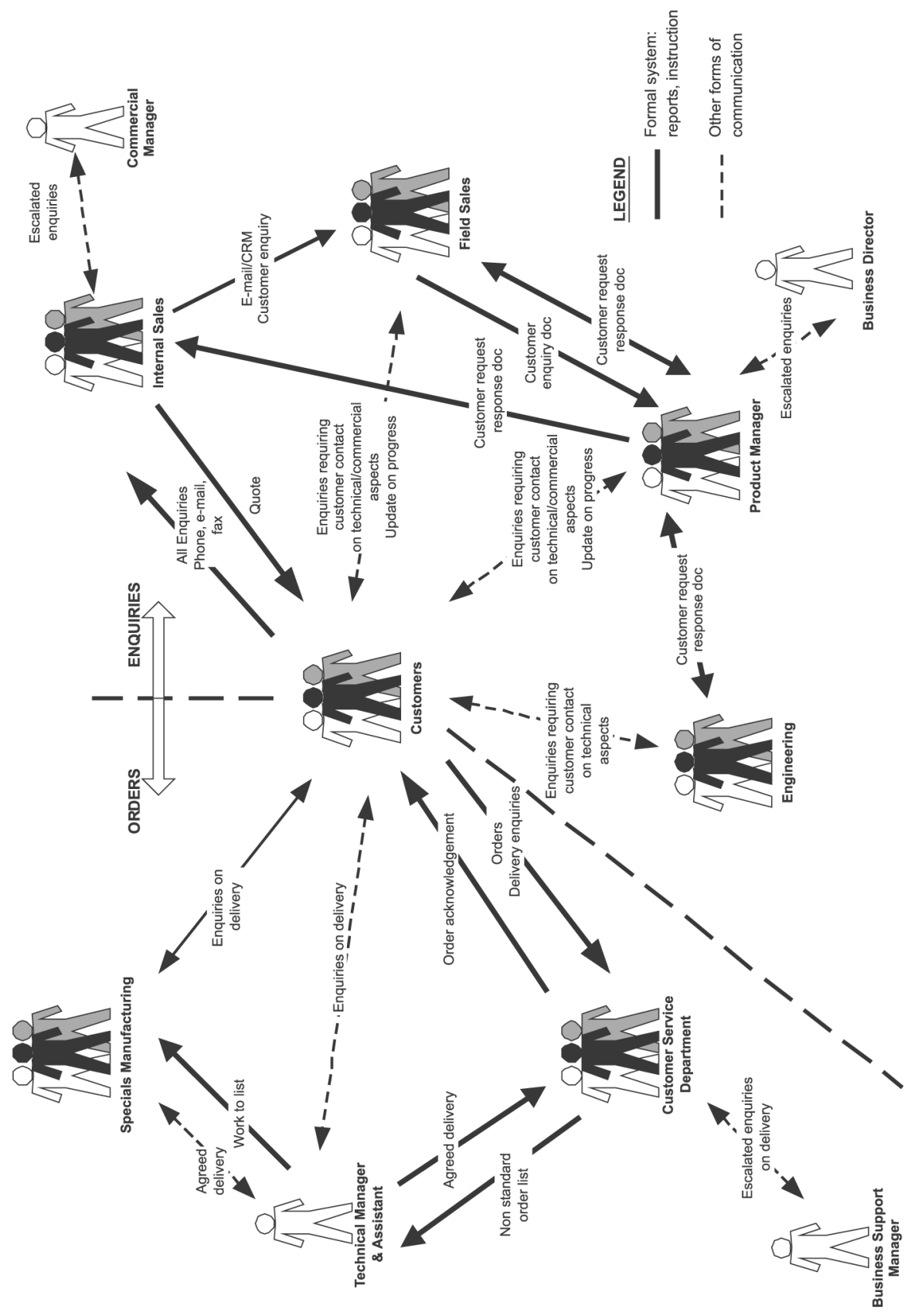

Figure 4. An example of a customer interface model at Custom Instrument 


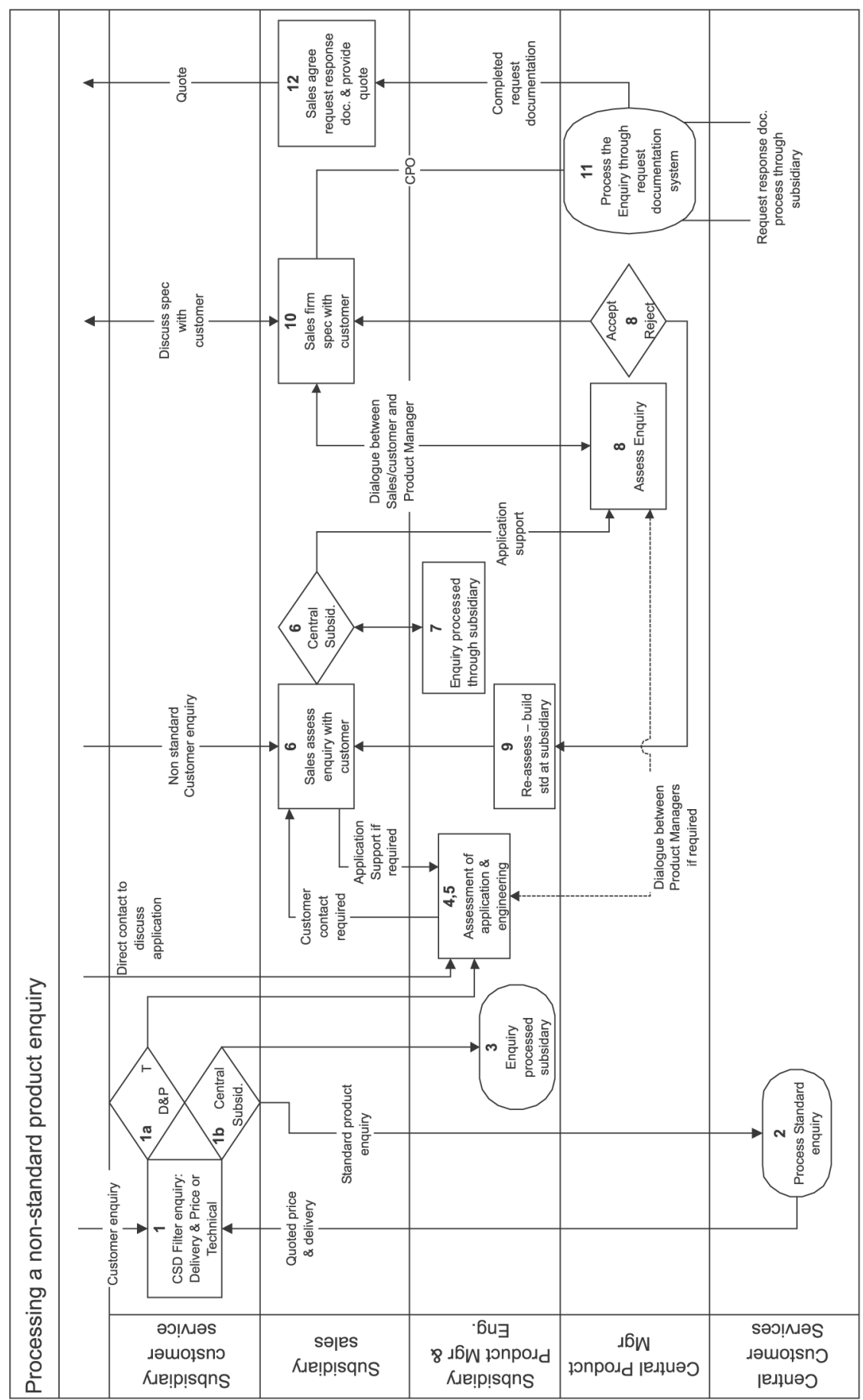

Figure 5. An example of a role activity diagram for the customer interface 
Decision centre (IV) - identification of information for reuse: In one of the subsidiaries a role has evolved for an individual who is proactive in identifying similar opportunities so that technical expertise that has been generated by previous quotations can be reapplied. This is effectively an offline role as an "applications consultant". All other technical experts are engaged in the day-to-day processing of requests. In this situation, it has been judged more effective to use an individual's knowledge rather than using an information system.

\section{Impact of variety on the quotation process}

We have identified two types of mechanisms for managing variety in the quotation process. The first we refer to as "absorbing" variety. A mechanism that absorbs variety is set-up to contain the effects of variety. It absorbs product variety with minimal impact on performance due to some intrinsic characteristics of the system, possibly how the system is managed. Table 3 shows some of the mechanisms that have been observed in the case studies for managing the impact of variety through absorption of variety.

\section{Table 3. Mechanisms for absorbing product variety through management of the quotation process}

\begin{tabular}{|c|c|c|}
\hline Mechanisms & Seat Selector & Custom Instrument \\
\hline \multicolumn{3}{|l|}{ Absorbing variety } \\
\hline $\begin{array}{l}\text { Process customer requests in } \\
\text { order of } \\
\text { importance and allocate } \\
\text { resources } \\
\text { accordingly }\end{array}$ & $\begin{array}{l}\text { Targets set for customer } \\
\text { response based on customer } \\
\text { rating }\end{array}$ & $\begin{array}{l}\text { The processing of customer } \\
\text { requests is prioritised by the } \\
\text { perceived commercial } \\
\text { opportunity at the individual } \\
\text { level }\end{array}$ \\
\hline $\begin{array}{l}\text { Meet a customer's needs with a } \\
\text { product specification of closest } \\
\text { appropriate fit }\end{array}$ & $\begin{array}{l}\text { Hierarchical support of sales } \\
\text { team by } \\
\text { operations and technical } \\
\text { managers }\end{array}$ & $\begin{array}{l}\text { Mainly autonomous } \\
\text { decision-making by product } \\
\text { specialists with collaborative } \\
\text { support from other functions }\end{array}$ \\
\hline & $\begin{array}{l}\text { One applications specialist } \\
\text { supports the sales team of } 80 \\
\text { people }\end{array}$ & $\begin{array}{l}\text { Six application specialists } \\
\text { within the central organisation } \\
\text { support seven national sales } \\
\text { representatives. There are } \\
\text { additional applications } \\
\text { specialists within subsidiary } \\
\text { companies }\end{array}$ \\
\hline $\begin{array}{l}\text { Update information systems } \\
\text { with efficient } \\
\text { use of resources }\end{array}$ & $\begin{array}{l}\text { Rules embedded within the } \\
\text { product } \\
\text { configurator replicate } \\
\text { component and costing changes } \\
\text { to the entire range }\end{array}$ & $\begin{array}{l}\text { Product model structure in the } \\
\text { configurator is such that } \\
\text { component changes need to be } \\
\text { replicated across each product } \\
\text { type }\end{array}$ \\
\hline $\begin{array}{l}\text { Monitor changing delivery } \\
\text { capabilities } \\
\text { according to the product variety } \\
\text { loading }\end{array}$ & $\begin{array}{l}\text { Standard delivery times - not } \\
\text { adjusted for production loading }\end{array}$ & $\begin{array}{l}\text { Deliveries estimated by specials } \\
\text { product team with designer. } \\
\text { However, this estimate needs to } \\
\text { be updated when the order is } \\
\text { placed }\end{array}$ \\
\hline
\end{tabular}


The second type of variety represents a different approach - mitigation of the impact of variety. These mechanisms are designed to deflect the impact of variety through proactive management of variety. Table 4 shows the mechanisms identified for mitigating the impact of variety. It is important to note that the quotation process provides an important source of information that allows mitigation of the impact of variety in other areas of the business such as product development and supply chain management.

\section{Discussion}

This section reviews process improvements and good practice for handling variety through quotation processes. First, we use the quotation process to review opportunities for process improvements. We also review the processes used by the two businesses for handling variety. Finally, we turn to the quotation process model - a key finding of this research - to make a critical review of the model. Extensions to the model and further work are discussed.

\section{Insights into quotation process improvements}

A generic model of quotation processes has been developed by this research to give insight into the functioning of the core process elements of the system - the decision centres. Reviewing an organisation's structure and the information systems infrastructure supporting these decision centres should lead to the

Table 4. Mechanisms for mitigating the impact of product variety through management of the quotation process

\begin{tabular}{|c|c|c|}
\hline Mechanisms & Seat Selector & Custom Instrument \\
\hline \multicolumn{3}{|l|}{ Mitigating the impact of variety } \\
\hline $\begin{array}{l}\text { Minimise the proliferation of } \\
\text { variety }\end{array}$ & $\begin{array}{l}\text { Listings of special } \\
\text { components are regularly } \\
\text { reviewed in order to } \\
\text { eliminate obsolete variants }\end{array}$ & $\begin{array}{l}\text { Lists of non-standard parts } \\
\text { are available to engineers. } \\
\text { Drawing database is } \\
\text { searched for similar designs } \\
\text { but this has limited success. } \\
\text { Reinvention of designs does } \\
\text { frequently occur }\end{array}$ \\
\hline $\begin{array}{l}\text { Filter requests by customers } \\
\text { for non-standard products }\end{array}$ & $\begin{array}{l}\text { Active steering towards } \\
\text { standard products }\end{array}$ & $\begin{array}{l}\text { Some steering towards } \\
\text { catalogue products through } \\
\text { informal processes }\end{array}$ \\
\hline $\begin{array}{l}\text { Rejection of customer } \\
\text { requests for infeasible or } \\
\text { "inappropriate" products }\end{array}$ & $\begin{array}{l}\text { Rejection of requests for } \\
\text { product that do not fit with } \\
\text { brand image }\end{array}$ & Rejection is rare \\
\hline $\begin{array}{l}\text { Monitor customer requests } \\
\text { in terms of types of } \\
\text { enquiries and orders }\end{array}$ & $\begin{array}{l}\text { All products are ordered } \\
\text { using the configurator. } \\
\text { Information systems allow } \\
\text { monitoring of demand to be } \\
\text { decomposed to the product } \\
\text { module level. This } \\
\text { information is used to } \\
\text { inform future product } \\
\text { development and supply } \\
\text { chain management }\end{array}$ & $\begin{array}{l}\text { Very limited - in the } \\
\text { process of setting up reports } \\
\text { on enquiries through CRM } \\
\text { system. The part coding } \\
\text { used by the configurator } \\
\text { and product structure } \\
\text { means that reports do not } \\
\text { give senior management the } \\
\text { information they would } \\
\text { wish for }\end{array}$ \\
\hline
\end{tabular}


identification of potential system or reorganisation improvements. The process modelling tools have allowed a structured review of processes. The process models provide a representation that is useful for cross-functional understanding of the entire process of conversion of customer requests into product orders. During model validation it was found that individuals had difficulty in either appreciating or confirming parts of process models and interaction diagrams outside their immediate area. The development of modelling techniques provides new tools for eliciting front-end process knowledge. These are useful for highlighting the contribution of an individual's knowledge and the informal networks they use.

On face value the differences between the two front-end systems could be attributed to the technical complexity of the products - instrumentation is far more complex and technically demanding than furniture. However, both companies respond to the same proportion of customer enquiries for "non-standard" products thus requiring agility in their processes to respond to new customer requirements. The study provides insights into how quotation processes can be "flexed" with customer-driven variety and how quotation systems can be managed in the broader context. At Custom Instrument there was evidence that the decision centres (I) and (II) were strongly supported by a "can do" attitude. Evidence was found of a strong motivation in all the front-end personnel to solve customers' problems. This was driven by senior management's customer orientation.

The study of Fisher et al. (1995) into the impact of variety on operations in automotive plants found that having a lean philosophy allowed factories to absorb high levels of variety with minimal impacts to performance. Analysis of the Custom Instrument case studies shows that the attitudes of people and organisational culture are an important mechanism in the absorption of variety. These attitudes allow problem-solving teams to be quickly assembled to address a customer's request and respond rapidly and effectively. The problem-solving mechanisms used by Custom Instrument relied on the formation of "virtual" teams for problem solving for a particular customer request. These teams were assembled using personal networks that allow organisational knowledge to be tapped effectively. The assembly of teams required flexibility of people and cross-functional collaboration.

Review of the processes for managing variety reveals that, although product configurator technologies may be powerful in enabling variety to be handled quickly and effectively, there are still human intensive activities in both the companies examined, e.g. support of the sales team by experts and "administering" of the configurator by the sales representative. Businesses should be aware that product configurators do not offer a panacea for automating the responses to customer requests.

\section{Management of decision centres - the "triage" concept}

The decision centres relate mainly to the processing of non-standard customer requests because the expertise of people is required to consider product specifications that are beyond the "hard-wired" product variant envelope contained in the configurator. However, the identification of information for reuse is directly related to the configurator because this decision centre can help to keep the configurator database live.

The classification decision centre is one of the most important decision centres for effective and efficient quotation processing. It is an area with a high concentration of organisational knowledge. It requires a 
customer request to be assessed and categorised. Some requests may be rejected and so the decision centre provides an important filter for variety. It is likely that at this stage customer needs will not be fully described in technical specification and, therefore, considerable applications knowledge may be required. An analogy is that of a "triage" nurse who assesses and prioritises an injured patient on arrival at a hospital. Considerable experience is required for this role. At Custom Instrument the "triage" role is provided by a team of people because of the diversity of knowledge required. The case study has highlighted the importance of the management of this decision centre. It needs to be managed carefully because all customer requests come through this "funnel".

\section{Process improvement opportunities}

Choosing the right level of automation to support variety will depend on how information systems may enable a business to compete and in particular which dimensions it is competing or customizing upon. If Custom Instrument were to move to the information systems model used by Seat Selector, more of the implicit knowledge held by individuals within the organisation would need to be externalised and proceduralised. There are few tools available to perform such a transformation of situation specific knowledge, although Neve (2003) among others provides generic knowledge elicitation tools. It is also worth questioning if, once the information is in a recordable format, the effort of updating the information system is worthwhile because the reuse of information is uncertain. Seat Selector have plans to use the concepts and software tools they employ for describing products in the product configurator - the rules for describing elements and restrictions as to how these elements can be pieced together - in other areas of the business. In particular, they have the capability to use this "process configuration" to provide further definition and automation of other processes with constraints, e.g. configuration of services. However, a balance needs to be sought between process formalisation and the need for flexibility in responding to customers (Welker and de Vries, 2001).

\section{Information reuse and mass customization}

The front-end of the organisation may be viewed as an information generating system (Reichwald et al., 2001), which creates information and knowledge as a result of customer interactions. Mass customization demands that the front-end processes create a solution to match the customer's needs for specification, cost, delivery and quality. The challenge is to enable efficient reuse of product, customer, applications and process information for creating customer solutions. Information technology offers the most efficient tools for repeatedly handling information. However, analysis of the Custom Instrument case study has highlighted the constraints that arise in achieving high levels of front-end automation; reliance on implicit organisational knowledge and a complex product applications architecture. Automation in this context would require the use of decision-making tools that could handle a multitude of interrelated factors with minimal effort required for updating. More sophisticated tools such as "process configuration" tools both for handling process knowledge (Child et al., 1991) and product related knowledge (Wongvasu et al., 2001) are being developed increasingly. This means that gaining the efficiencies demanded by mass customization are potentially more feasible. It can also be argued that dynamic response by a team of human experts may be more effective in some environments than attempting to fully automate a quotation process. 
It is worth noting that in neither company did information systems - ERP and configurators - offer a panacea for providing quotations. The human contribution to these processes was critical. Product modularity is emphasised as essential for the implementation of product configuration systems (Forza and Salvador, 2002). A modular product architecture was a precursor to the implementation of the configurator system in both companies. After implementation there was significant resource required for ongoing management of the product assortment described by the configurator. The mechanisms for mitigating the impact of variety describe some of the practices that were used to manage the dynamic envelope whilst aiming to gain the benefits of the product configurator.

\section{Testing the applicability of the quotation model}

An important part of theory development is to test generalizations to find out the circumstances in which the theory does not hold. The model has been developed from two case studies and whilst it is based on in-depth analysis of the cases to provide robustness of theory, further confirmation is still required to ensure the applicability of the theory to a wider context. This section reviews the conceptual models of the quotation processes in different contexts.

The quotation process model suggests that four decision centres should be present in an organisation. Providing there is some element of customer-driven variety this is likely to be the case because there needs to be mechanisms for conveying the customer's requirements to the organisation. However, differences may evolve in the decision centres according to their relative importance. Some decision centres are likely to be more important than other decision centres in different contexts. Table 5 lists some instances where certain decision centres may be less significant.

This highlights that for extremes of very low or very high variety some decision centres may be less significant. This may mean that the quotation model of four decision centres is not applicable in these contexts. We would suggest that many companies exist in the mid variety range; that companies with very low or very high levels of rates of change of variety are fewer in number. Also, variety surveys show that there are relatively few companies that have homogeneous markets in today's dynamic business environments (Funke and Ruhwedel, 2000).

\section{Table 5. Evaluation of decision centre concepts}

Decision centre Business environment in which decision centre is less significant
DC (I)
All configured through automatic rules. Product envelope static or intelligent system can cater for all scenarios
DC (II)
Customer requests are homogeneous
DC (III)
Customers are homogeneous
DC (IV)
Low opportunity to reuse request information - high variability
of requests 
Towards the development of a system for classifying quotation processes

An extension to the quotation process model is based on the relative importance of the four decision centres in any particular context. It is predicted that a customization business will have a dominant decision centre and that this decision centre is determined by environmental characteristics. This leads to a classification system forquotation processes based on the most significant decision centre. This significant decision centre is likely to represent the decision centre consuming the most resource and may offer the focus for future process improvements. Figure 6 shows each of the four categories and the terms that are used to refer to each category of front-end systems; these are value proposition, proposal, competitive bidding and high-frequency quotation. The table also shows how the two case studies investigated in this analysis have been classified; the quotation processes of custom instrument have been classified as "proposal" and seat selector as "high-frequency quotation". Further, work is required to confirm the prevalence of each category. Further, validation may be achieved by conducting a survey of manufacturers of industrial products to test the fit of the typology. Such a survey should explore therelationships between environmental drivers and specific decision centre dominance.

\begin{tabular}{|c|c|c|}
\hline Focal decision centre & Characteristics & Process termed as: \\
\hline \multicolumn{3}{|l|}{ DC(I) } \\
\hline & $\begin{array}{l}\text { Providing a customer } \\
\text { solution }\end{array}$ & Value proposition \\
\hline \multicolumn{3}{|l|}{ DC(II) } \\
\hline & $\begin{array}{l}\text { Risk assessment - routing } \\
\text { to key experts for high } \\
\text { accuracy }\end{array}$ & $\begin{array}{l}\text { Proposal } \\
\text { (CustomInstrument) }\end{array}$ \\
\hline \multicolumn{3}{|l|}{ DC(III) } \\
\hline & $\begin{array}{l}\text { Speed and accuracy } \\
\text { important }\end{array}$ & Competitive bidding \\
\hline \multicolumn{3}{|l|}{ DC(IV) } \\
\hline & $\begin{array}{l}\text { Information reuse } \\
\text { important for economies }\end{array}$ & High frequency quotation \\
\hline & & (SeatSelector) \\
\hline
\end{tabular}

Figure 6. Classification of quotation processes according to decision centre 


\section{Conclusions}

The aim of this research study was to capture and analyse quotation processes of two very different businesses in high-variety environments. They have similarities in the fact that both use a product configurator and both respond to customer requests for non-standard products outside the existing variety envelope (which is itself dynamic and continually evolving). Examination of the two businesses has provided evidence of the mechanisms that are beneficial in managing high product variety. We offer a model of the quotation process in this context. Existing theory in this area does not acknowledge the desirability and difficulties in reusing knowledge generated by a quotation process. The quotation process model presented in this paper differs from existing theory in this area because it recognises that

(1) effectively managing the dynamic variety envelope in high-variety environments is both essential and challenging;

(2) businesses are increasingly adopting product configurator and customer relationship technologies and systems; and

(3) human expertise and decision making are necessary in many cases to respond to non-standard orders and to manage the process.

Analysis of case studies of businesses operating in high-variety environments that provide both configured and responsively engineered products has revealed that the product configurator does offer support for some of the information and decision burdens arising from high variety. However, quotation processes are still strongly people intensive - analysis of quotation processes has highlighted how businesses are reliant on many informal practices. This is important process knowledge, which needs to be understood by an organisation concerned about the effectiveness and responsiveness of its quotation processes. The research has presented models to provide insights into these complex informal practices. It has also highlighted important generic strategies for absorbing and mitigating the impact of high variety in quotation processes. Further research is needed to provide explanatory models that can lay the basis for the design and management of quotation processes in specific contexts.

\section{Acknowledgement}

The work has been funded by an Engineering and Physical Sciences Research Council grant to the Nottingham Innovative Manufacturing Research Centre. We would like to thank the industrialists who have participated in this research.

\section{References}

Amaro, G., Hendry, L. and Kingsman, B.K. (1999), "Competitive advantage, customisation and a new taxonomy for non make-to-stock companies", International Journal of Operations \& Production Management, Vol. 19, pp. 349-71.

Anderson, S. (1995), "Measuring the impact of product mix heterogeneity on manufacturing overhead cost", The Accounting Review, Vol. 70, pp. 363-87.

Child, P., Diederichs, R., Sanders and Wisniowski, S. (1991), "SMR Forum: the management of complexity", Sloan Management Review, Vol. 33, pp. 73-85. 
De Bono, E. (1998), Simplicity, Penguin, London.

Erens, F.J. and Hegge, H.M.H. (1994), "Manufacturing and sales co-ordination for product variety", International Journal of Production Economics, Vol. 37, pp. 83-99.

Forza, C. and Salvador, F. (2002), "Managing for variety in the order acquisition and fulfilment process: the contribution of product configuration systems", International Journal of Production Economics, Vol. 76, pp. 87-98.

Fisher, M., Jain, A. and MacDuffie, J. (1995), "Strategies for product variety: lessons from the auto industry", in Bowman, E. and Kogut, B. (Eds), Redesigning the Firm, Oxford University Press, New York, NY, pp. 116-54.

Funke, M. and Ruhwedel, R. (2000), "Product variety and economic growth - empirical evidence for the OECD countries", International Monetary Fund, Vol. 48 No. 2, pp. 225-42.

Hayes, R. and Wheelwright, S. (1984), Restoring Our Competitive Edge, Wiley, New York, NY.

Holweg, M. and Greenwood, A. (2000), "Product variety, life-cycles and rate of innovation", Proceedings of the 2000 Logistics Research Network Conference, Cardiff.

Kingsman, B. and de Souza, A.A. (1997), "A knowledge-based decision support system for cost estimation and pricing decisions in versatile manufacturing companies", International Journal of Production Economics, Vol. 53, pp. 119-39.

Kruse, G. and Bramham, J. (2003), "You choose", Manufacturing Engineer, August/September pp. 34-7 .

McCutcheon, D., Raturi, A. and Meredith, J.R. (1994), "The customization-responsiveness squeeze", Sloan Management Review, Winter, pp. 89-99.

McDermott, C.M., Greis, N.P. and Fischer, W.A. (1997), "The diminishing utility of the product/process matrix: a study of the US power tool industry", International Journal of Operations \& Production Management, Vol. 17, pp. 65-84.

MacCarthy, B., Brabazon, P.G. and Bramham, J. (2003), "Fundamental modes of operations for mass customization", International Journal of Production Economics, Vol. 85, pp. 289-304.

MacDuffie, J.P., Sethuraman, K. and Fisher, M.L. (1996), "Product variety and manufacturing performance: evidence from the international automotive plant study", Management Science, Vol. 42, pp. 350-69.

Miles, M.B. and Huberman, M. (1994), Qualitative Data Analysis, Sage, CA.

Miller, J.G. and Vollman, T.E. (1985), "The hidden factory", Harvard Business Review, September-October, pp. 142-52.

Moos, C. and Milling, P. (2002), "Customer-orientated manufacturing strategies", Proceedings of the EUROMA Conference, Copenhagen, Vol. 2, pp. 993-1002.

Neve, T. (2003), "Right questions to capture knowledge", Electronic Journal of Knowledge Management, Vol. 1 No. 1, pp. 47-54, available at: www.ejkm.com/

Ould, M.A. (1995), Business Processes: Modelling and Analysis for Re-engineering and Management, Wiley, Chichester. 
Pettigrew, A.M. (1992), "The character and significance of strategy process research", Strategic Management Journal, Vol. 13, pp. 5-16.

Pine, B.J. (1993), "Standard modules allow mass customization at Bally Engineering Structures", Planning Review, Vol. 21 No. 4, pp. 20-2.

Reichwald, R., Zanner, S. and Jaeger, S. (2001), "Creating individualized solutions in decentralized, customer-centric production units: investigations from an economic perspective", Proceedings of the First World Congress on Mass Customization and Personalization, Hong Kong, (CD-ROM).

Sievanen, M., Suomala, P. and Paranko, J. (2000), "Cost of customization", Proceedings of the 16th International Conference of Production Research, Prague.

Skinner, W. (1974), "The focussed factory", Harvard Business Review, May-June, pp. 113-21.

Spring, M. and Darymple, J. (2000), "Production customisation and manufacturing strategy", International Journal of Operations and Production Management, Vol. 20, pp. 441-67.

Stalk, G. Jr (1988), "Time - the next source of competitive advantage", Harvard Business Review, Vol. 66, pp. 41-51.

Starr, M. (1965), "Modular production - a new concept", Harvard Business Review, November-December, pp. 131-42.

Swaminathan, J.M. (2001), "Enabling customization using standard operations", California Management Review, Vol. 43, pp. 125-36.

Toffler, A. (1970), Future Shock, Bantam, New York, NY.

Voss, C., Tsikriktsis, N. and Frohlich, M. (2002), "Case research in operations management", International Journal of Operations \& Production Management, Vol. 22, pp. 195-219.

Welker, G.A. and de Vries, J. (2001), "Formalisation and flexibility in order management", Proceedings of the EUROMA Conference, Bath Vol. 2, pp. 1212-25.

Wongvasu, N., Karmarthi, S. and Zeid, I. (2001), "Case based reasoning for rapid estimation of mass customized products", Proceedings of the First World Congress in Mass Customization and Personalization, Hong Kong, (CD-ROM).

Yeh, K. and Chu, C. (1991), "Adaptive strategies for coping with product variety decisions", International Journal of Operations and Production Management, Vol. 11, pp. 35-7.

\section{Further reading}

Chung, P.W.H., Cheung, L., Stader, J., Jaris, P., Moore, J. and Macintosh, A. (2003), "Knowledge-based process management", Knowledge-Based Systems, Vol. 16, pp. 149-60.

\section{To cite this paper:}

Bramham, J., MacCarthy, B., \& Guinery, J. (2005). Managing product variety in quotation processes. Journal of Manufacturing Technology Management, 16(4), 411-431. 